\title{
Methyl bromide and methyl chloride fluxes from temperate forest litter
}

\author{
Emanuel Blei ${ }^{\mathrm{a}, \mathrm{b}}$, Mathew R. Heal ${ }^{\mathrm{a}, *}$ \\ ${ }^{a}$ School of Chemistry, University of Edinburgh, Joseph Black Building, West Mains \\ Road, EH9 3JJ Edinburgh, UK \\ ${ }^{b}$ School of GeoSciences, University of Edinburgh, Crew Building, West Mains Road, EH9 \\ 3JN Edinburgh, $U K$
}

\begin{abstract}
Methyl halide fluxes were measured from fine (nonwoody) litter samples in a temperate deciduous forest site in Scotland on 16 occasions over more than a year and from a coniferous forest site. The resulting mean $( \pm 1 \mathrm{sd}) \mathrm{CH}_{3} \mathrm{Br}$ and $\mathrm{CH}_{3} \mathrm{Cl}$ fluxes were $4.1 \pm 3.7 \mathrm{ng} \mathrm{kg}^{-1} \mathrm{~h}^{-1}$ and $0.98 \pm 0.62 \mathrm{\mu g} \mathrm{kg}^{-1} \mathrm{~h}^{-1}$, respectively, for dry mass leaf litter and $5.7 \pm 6.3 \mathrm{ng} \mathrm{kg}^{-1} \mathrm{~h}^{-1}$ and $0.47 \pm 0.14 \mathrm{\mu g} \mathrm{kg}^{-1} \mathrm{~h}^{-1}$ for dry mass needle litter. Temporal variations of net fluxes from leaf litter were significantly greater than spatial variations suggesting seasonality in the fluxes. The mean $\mathrm{CH}_{3} \mathrm{Cl} / \mathrm{CH}_{3} \mathrm{Br}$ mass ratio of fluxes was $\sim 200$, an order of magnitude larger than the ratio of their estimated global turnovers. Temperate forest litter may be a moderate net source of $\mathrm{CH}_{3} \mathrm{Cl}$ globally but a negligible source of $\mathrm{CH}_{3} \mathrm{Br}$. These statements refer to the nonwoody litter component only.
\end{abstract}

Keywords: methyl halides, leaf litter, temperate, forest

\section{Introduction}

During the last few years a persistent shortfall in estimates of known sources against known sinks of global $\mathrm{CH}_{3} \mathrm{Br}$ and $\mathrm{CH}_{3} \mathrm{Cl}$ budgets has been noted, with up to a quarter of the emissions of these two gases needed to balance the global budgets not accounted for with currently available data (Montzka et al., 2002; Clerbaux et al., 2007; Yvon-Lewis et al., 2009). These

\footnotetext{
*Corresponding author

Email address: m.heal@ed.ac.uk (Mathew R. Heal)
} 
8

two methyl halide gases are the main natural vectors of bromine and chlorine into the stratosphere, where they account for $37 \%$ and $16 \%$ of bromine and chlorine related ozone loss, respectively (Fahey, 2007).

Amongst many others, leaf litter has been proposed as a potential globally important source of $\mathrm{CH}_{3} \mathrm{Br}$ and $\mathrm{CH}_{3} \mathrm{Cl}$ (Watling and Harper, 1998; Lee-Taylor and Holland, 2000; Hamilton et al., 2003; Drewer et al., 2008; Wishkerman et al., 2008) but has not been widely studied. This study was therefore established to examine the potential impact of leaf litter from temperate forests on global methyl halide budgets.

Temperate forests are estimated to account for a global land area of $27.9 \times 10^{12} \mathrm{~m}^{2}$ (UNESCO, 1973; Matthews, 1997) and have the potential to produce or to remove large amounts of methyl halides through a number of sources and sinks. Potential sources include higher plants (Drewer et al., 2008), forest soils (Dimmer et al., 2001; Drewer et al., 2008), litter (Hamilton et al., 2003; Drewer et al., 2008; Wishkerman et al., 2008), and the fungi often associated with litter (Watling and Harper, 1998; Lee-Taylor and Holland, 2000) whilst reported sinks comprise forest soils (Serca et al., 1998; Rhew et al., 2003) and higher plants (Jeffers et al., 1998).

Of these four forest components (plants, soils, litter and fungi) this study concentrates on small nonwoody detritus (leaves and needles). The reason for this interest is that even small fluxes per unit mass could result in sizeable global fluxes when considering the large extent of temperate forest cover. Moreover, there are to date no field data on $\mathrm{CH}_{3} \mathrm{Cl}$ fluxes from temperate forest litter although it has been shown to be a potentially important source of $\mathrm{CH}_{3} \mathrm{Br}$ by our group (Drewer et al., 2008), from measurements made during autumn and winter. Another study by our group in Borneo, SE Asia, estimated that $\mathrm{CH}_{3} \mathrm{Br}$ and $\mathrm{CH}_{3} \mathrm{Cl}$ net flux from tropical forest leaf litter could account for $\sim 0.1 \%$ and $\sim 7 \%$ of the respective global budgets (Blei et al., 2010a). It is also of interest to examine if any potential source is seasonal to improve information for extrapolation to global budgets.

Two laboratory studies examining the possibility of abiotic production of methyl halides by Hamilton et al. (2003) and Wishkerman et al. (2008) reported that $\mathrm{CH}_{3} \mathrm{Cl}$ and $\mathrm{CH}_{3} \mathrm{Br}$ fluxes negatively correlate with leaf litter water content and this was also investigated in this work. 


\section{Field locations}

The main field location was Fir Links forest, a 2.05 ha mixed beech ( Fagus sylvatica) and sycamore (Acer pseudoplatanus) woodland planted in 1954, situated adjacent to the North Sea coastline within the John Muir Country Park, East Lothian, Scotland $\left(56^{\circ} 0.1^{\prime} \mathrm{N} 002^{\circ} 35.7^{\prime} \mathrm{W}\right)$. The site is not cleared of smaller debris and has a perennial layer of leaf litter. During the study, ground vegetation was either sparse or absent and consisted of ferns of varying density. Topographically the site had very few features, being situated on a plateau a few metres above sea level. 124 enclosures on 76 samples were taken on 16 occasions starting on the $30^{\text {th }}$ April 2008 until the $28^{\text {th }}$ July 2009.

The second site was Griffin Forest $\left(56^{\circ} 37^{\prime} \mathrm{N} 003^{\circ} 38^{\prime} \mathrm{W}\right)$, a Sitka spruce $(P i$ cea sitchensis) plantation of 3862 ha planted in 1981, situated $350 \mathrm{~m}$ above sea level near the town of Aberfeldy in Perthshire, Scotland (Ibrom et al., 2006). Ten samples were taken on the $24^{\text {th }}$ June 2009, 5 samples each from a thinned and an un-thinned section of the forest. An earlier attempt to quantify litter methyl halide fluxes at this site failed due to unexpectedly high emissions so only data from the one sampling occasion are available.

\section{Methodology}

Methyl halide fluxes were measured using static enclosures in situ over durations of $10 \mathrm{~min}, 1 \mathrm{~h}, 6 \mathrm{~h}$ or $24 \mathrm{~h}$. The different enclosure durations were used to accommodate different flux strengths and to overcome the dual problems of non-linear fluxes during long enclosure times and low precisions at short enclosure times (see later).

\subsection{Enclosures}

Enclosures were opaque $12 \mathrm{~L}$ polypropylene buckets with air-tight lids and a sampling port made of a $1 \mathrm{~mL}$ syringe fitted with an approximately $7 \mathrm{~cm}$ long rubber tube that was connected to a three-way valve. Typically 250 to $400 \mathrm{~g}$ of fresh leaf/needle litter was placed into each bucket and then enclosed for either $10 \mathrm{~min}, 1 \mathrm{~h}, 6 \mathrm{~h}$ or $24 \mathrm{~h}$, after which $\sim 550 \mathrm{~mL}$ of headspace sample was transferred to an empty Tedlar bag which was analysed within a day or two of collection.

Depending on the density of the litter layer on the ground, each sample represented a few square metres of forest floor litter. The number of buckets employed for a measurement ranged from 2 to 18 at any time. Except for 
measurements at Fir Links on the $30^{\text {th }}$ April 2008, fluxes were measured against a blank enclosure. A small temperature data logger monitored the temperature inside a blank bucket during enclosures.

\subsection{Determination of fresh mass, dry mass and water content}

Sampled leaf/needle litter materials were brought to the laboratory and the fresh mass recorded. The litter was then placed into paper bags and dried in an oven at $70^{\circ} \mathrm{C}$ to derive dry mass. All water content values are expressed gravimetrically as $\% \mathrm{w} / \mathrm{w}$ fresh mass.

\subsection{Correction for litter volumes in enclosures}

To acquire an accurate estimate of an enclosed headspace volume the volume of fresh leaf or needle litter in each was subtracted. Dry litter volumes were derived by measuring the mean specific volume of oven dried $\left(70^{\circ} \mathrm{C}\right)$ leaf/needle litter via water displacement on six $50 \mathrm{~g}$ replicate samples and multiplication with the dry masses of the individual litter samples. The dry litter volume as well as the volume of the water originally contained in the fresh, wet litter sample was subtracted from the enclosure volume.

\subsection{Bromine and chlorine content of plant material}

Bulked samples of litter material collected from both sites in July 2009 were analysed for chlorine and bromine content by Dr. A. K. Cheburkin of the University of Heidelberg using the TITAN-XRF, an energy-dispersive X-ray fluoresecnce instrument custom built for the analysis of peat and plant species (Cheburkin and Shotyk, 2005). Before shipping to Germany in airtight zipper-bags the litter and needle material was first washed with deionised water, dried in an oven at $70^{\circ} \mathrm{C}$ to constant mass and ground. Limits of detection were 0.3 and $80 \mathrm{mg} \mathrm{kg}^{-1}$ for bromine and chlorine, respectively, with analytical uncertainty estimated to be less than $10 \%$.

\subsection{Testing for spatial variability of methyl halide fluxes}

At Fir Links (the deciduous forest) normally 3 buckets were filled with leaf litter from a randomly-chosen position within the forest since it was not possible to collect leaf litter from the same spot every time. As this made it impossible to differentiate between temporal and spatial variations in fluxes, on two occasions fluxes were measured in duplicate from nine points of a $50 \mathrm{~m} \times 50 \mathrm{~m}$ square with sampling points every $25 \mathrm{~m}$ in each direction. Three blank enclosures were also included. The data from these two studies 
were used to compare spatial with temporal variation of fluxes throughout the year.

At Griffin Forest five litter samples each were collected from a previously thinned, light, relatively dry area and from an un-thinned, dark, relatively wet area. Fluxes were calculated against the mean of two parallel blank samples.

\subsection{Dependency of fluxes on enclosure time}

As already stated, fluxes quantified using static enclosure methods may vary with length of enclosure time because the accumulation/depletion of $\mathrm{CH}_{3} \mathrm{Br}$ and $\mathrm{CH}_{3} \mathrm{Cl}$ inside the enclosure can alter the behaviour of the relevant processes. Emissions from leaf litter were highly variable in magnitude and often very low. This necessitated long enclosure times to achieve concentrations that were more accurately quantifiable. However, when emissions were higher than usual, longer enclosure times may modify fluxes to appear smaller per unit time than in the absence of enclosure.

To quantify variation in derived flux with enclosure duration, measurements of a batch of litter were regularly repeated with different enclosure times: 6 and/or $24 \mathrm{~h}$ at Fir Links; $10 \mathrm{~min}$ and $1 \mathrm{~h}$ at Griffin Forest. Table 1 shows the mean ratios of fluxes obtained from those experiments where fluxes were derived using two different enclosure durations on a given sample. For final comparative interpretation of fluxes at a given site, fluxes were expressed relative to a common enclosure time of $6 \mathrm{~h}$ and $10 \mathrm{~min}$ for Fir Links and Griffin Forest, respectively, as follows. Fluxes derived from enclosures of the duration specified were used without modification. Where flux values at the shorter duration were not available for a specific sample or below the limit of detection (LOD) they were obtained by multiplying the flux derived from the longer-duration enclosure using the relevant ratio given in the table.

Table 1: Mean ratios of fluxes (and supporting statistical data) obtained from the different enclosure durations specified, for litter material at the two field locations. All correlations shown are statistically significant at $P<0.05$.

\begin{tabular}{lrrrrrrrr}
\hline & \multicolumn{3}{c}{$\mathrm{CH}_{3} \mathrm{Br}$} & & & \multicolumn{3}{c}{$\mathrm{CH}_{3} \mathrm{Cl}$} \\
\cline { 2 - 4 } \cline { 7 - 9 } Site & ratio & $R$ & & & ratio & $R$ & $n$ \\
\hline Fir Links, 6 h/24 h & 2.40 & 0.94 & 28 & & 5.71 & 0.99 & 22 \\
Griffin Forest, 10 min/1 h & 6.77 & 0.97 & 10 & & 2.16 & 0.95 & 4 \\
\hline
\end{tabular}




\section{7. $G C$ analysis}

Methyl halide determination by GC-ECD was conducted as described in Hardacre et al. (2009) and Blei et al. (2010a). Net fluxes were derived from the difference between sample and blank enclosure values and expressed per dry litter mass. Uncertainties in individual flux values comprise uncertainties in both instrumental determination of methyl halide concentration in a gas sample and in the enclosure parameters used to convert concentrations to flux. The main source of uncertainty derives from interpolation of the calibration curve. Since both the parallel blank and enclosure samples were stored and analysed in identical conditions such uncertainties are minimised by the experimental design of quantification by difference.

Discrimination of a significant net flux depends on the ability to determine significant difference in analyte mixing ratio between an enclosure sample and parallel blank sample. The LOD for determination of a net flux was thus set at twice the uncertainty in the associated background sample. The LOD values vary between individual flux measurements because the uncertainties in individual sample and background gas analyses, and in estimation of enclosed volume and foliage mass, vary between measurements. As illustration, the interquartile ranges of blank fluxes for $\mathrm{CH}_{3} \mathrm{Br}$ at Fir Links and Griffin Forest were estimated to be 0.6 and $7 \mathrm{ng} \mathrm{kg}^{-1} \mathrm{~h}^{-1}$, respectively, and for $\mathrm{CH}_{3} \mathrm{Cl}$ fluxes, 0.007 and $0.06 \mu \mathrm{g} \mathrm{kg}^{-1} \mathrm{~h}^{-1}$ at the two sites, respectively. Negative fluxes are necessarily semi-quantitative since methyl halide uptake was limited by the initial concentrations inside the enclosure and any positive flux from the chamber material itself during the enclosure time.

All quoted sd values combine analytical and concentration-to-flux conversion uncertainties, plus, for mean values, the variation between individual measurements.

\section{Results and Discussion}

Leaf/needle litter chlorine content was $<80 \mu \mathrm{gg}^{-1}$ dry wt at both sites whilst mean bromine content was 11.5 and $3.5 \mathrm{\mu gg}^{-1}$ dry wt at Fir Links (deciduous) and Griffin Forest (conifereous), respectively. Bromine concentration in the leaf litter was therefore almost three times the concentration in the needle litter, probably due to the coastal location of Fir Links. The bromine concentration for Fir Links litter was in good agreement with the value of $8.75 \mathrm{\mu g} \mathrm{g}^{-1}$ given by Lee-Taylor and Holland (2000) for fine woody matter from coastal regions. No information could be found for bromine content 
of coniferous litter for comparison with the Griffin Forest data. Whilst the $<80 \mathrm{\mu g} \mathrm{g}^{-1}$ concentration for chlorine in this work is low in comparison with the values of 1100 and $2100 \mathrm{\mu g} \mathrm{g}^{-1}$ for fresh leaves from two Fagus species reported by Yassaa et al. (2009), it is more in line with the much lower chlorine content of $\sim 126 \mathrm{\mu g} \mathrm{g}^{-1}$ dry wt reported by Lobert et al. (1999) for temperate leaf litter rather than fresh plant material.

\subsection{Fir Links (deciduous litter)}

Net methyl halide fluxes at the deciduous wood were found to vary strongly with time (Figure 1). Whilst fluxes for most of the year were often very small and mostly slightly negative (uptake) there were two incidences of large positive net fluxes (production) during September 2008 and March 2009. Due to their magnitude these fluxes dominated the mean annual flux although most of the time leaf litter took up methyl halides. This result is important as it shows that fluxes must be monitored over long periods of time to gain confidence in the long-term mean direction and magnitude of fluxes in an ecosystem.

It is very likely that elevated fluxes during autumn were due to the fall of fresh leaf litter from the canopy and the elevated fungal and microbial decomposition activity at this time of year, known to yield methyl halides (Watling and Harper, 1998; Lee-Taylor and Holland, 2000). Elevated leaflitter $\mathrm{CH}_{3} \mathrm{Br}$ fluxes in autumn, declining over winter, were also reported by Drewer et al. (2008). No substantiated explanation can be offered for the other event, but it is likely relevant that it coincided with the pronounced rise in ambient air temperatures at the end of a prolonged winter cold period, suggesting a 'kick-start' in (bio)chemical activity. The mean $( \pm 1 \mathrm{sd})$ annual fluxes expressed per hour were $4.1 \pm 3.7 \mathrm{ng} \mathrm{kg}^{-1} \mathrm{~h}^{-1}$ and $0.98 \pm 0.62 \mathrm{\mu g} \mathrm{kg}^{-1} \mathrm{~h}^{-1}$ for $\mathrm{CH}_{3} \mathrm{Br}$ and $\mathrm{CH}_{3} \mathrm{Cl}$, respectively.

\subsubsection{The relationship between $\mathrm{CH}_{3} \mathrm{Br}$ and $\mathrm{CH}_{3} \mathrm{Cl}$ net fluxes}

As is readily visible from Figure 1, fluxes of these two gases followed very similar temporal trends, and the linear correlation between the two was highly significant $(R=0.81, P=0.0002)$. This is a clear suggestion that net fluxes are the result of the same process(es).

The $\mathrm{CH}_{3} \mathrm{Cl} / \mathrm{CH}_{3} \mathrm{Br}$ mass ratio of the average net fluxes was $\sim 240$ which corresponds to a $\mathrm{Cl} / \mathrm{Br}$ mass ratio in methyl halide fluxes of $\sim 200$. The $\mathrm{CH}_{3} \mathrm{Cl} / \mathrm{CH}_{3} \mathrm{Br}$ flux mass ratio is therefore an order of magnitude greater than the mass ratio of the global budgets of the two gases (Montzka et al., 


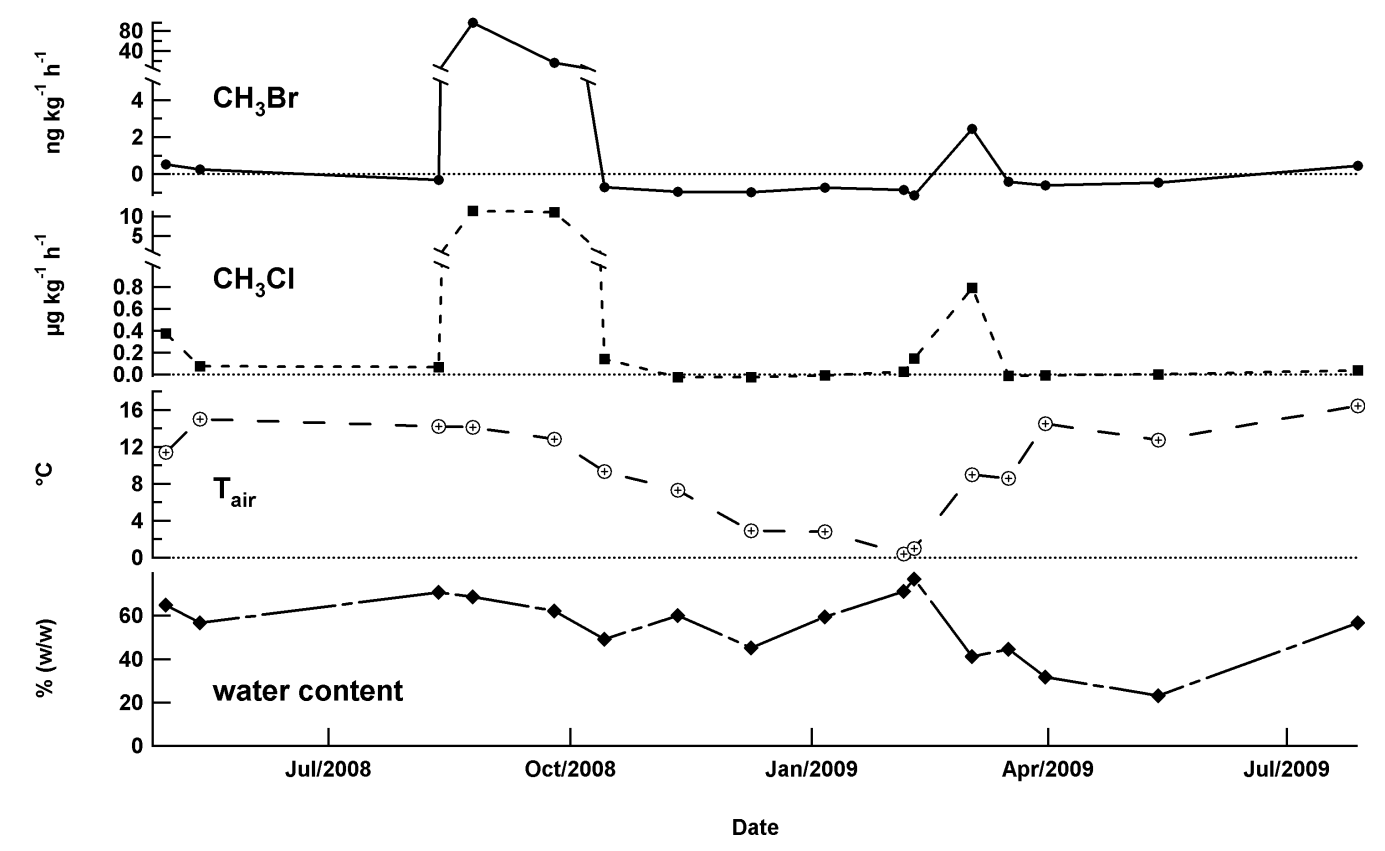

Figure 1: Net $\mathrm{CH}_{3} \mathrm{Br}$ and $\mathrm{CH}_{3} \mathrm{Cl}$ fluxes from leaf litter at Fir Links measured from $30^{\text {th }}$ April 2008 to $28^{\text {th }}$ July 2009 together with mean enclosure temperature and litter gravimetric water content.

2002; Clerbaux et al., 2007), indicating that temperate deciduous litter is relatively more important as a $\mathrm{CH}_{3} \mathrm{Cl}$ source than as a $\mathrm{CH}_{3} \mathrm{Br}$ source, as was also concluded for tropical vegetation and litter (Blei et al., 2010a). The $\mathrm{CH}_{3} \mathrm{Cl} / \mathrm{CH}_{3} \mathrm{Br}$ average emission mass ratio observed here is also broadly similar to the $\mathrm{Cl} / \mathrm{Br}$ mass ratio of $\sim 280$ found in sea water (likely the dominant source of halogen in near-coast surface environment). In contrast, findings from several studies of salt marsh vegetation show a strong preference for $\mathrm{CH}_{3} \mathrm{Br}$ over $\mathrm{CH}_{3} \mathrm{Cl}$ net emission (Rhew et al., 2000; Dimmer et al., 2001; Cox et al., 2004; Drewer et al., 2006; Manley et al., 2006; Blei et al., 2010b), but the latter are living halophytes, not decaying litter, so differences are not unexpected and presumably reflect different underlying causal processes for emissions.

\subsubsection{Spatial vs. temporal variations in methyl halide fluxes}

The two detailed studies involving 9 sample pairs each on the $9^{\text {th }}$ February and $28^{\text {th }}$ July 2009 revealed that net fluxes for both gases varied spatially significantly less than they did over time (one-tailed $F$-test at $P<0.05$ ). Al- 
though not direct proof, this evidence and the fact that fluxes during autumn were orders of magnitudes larger than during the rest of the year, indicates that spatial flux variations were negligible compared to temporal variations. This supports the sampling strategy of taking samples from varying locations on each sampling occasion.

\subsubsection{Statistical analysis of possible drivers}

Statistical analysis (two-tailed $t$-test at $P<0.05$ ) did not reveal any significant correlation between net methyl halide fluxes and ambient air temperature (up to $16^{\circ} \mathrm{C}$ ) or leaf litter water content over the monitoring period. This is consistent with previous findings from a study, also with bulk litter, in the tropical rainforest of Borneo (Blei et al., 2010a) but different to the two laboratory studies by Hamilton et al. (2003) and Wishkerman et al. (2008) which showed correlation with temperatures over the (non-overlapping) higher temperature range of $25-35^{\circ} \mathrm{C}$.

\subsubsection{Comparison with previous studies}

Only two previous studies have been carried out on methyl halide emissions from in situ leaf litter. The first, by Drewer et al. (2008), at the Hermitage of Braid woodland site in southern Edinburgh, Scotland, examined $\mathrm{CH}_{3} \mathrm{Br}$ fluxes only and found mean ( \pm sd) net emission from temperate deciduous leaf litter of $43 \pm 33 \mathrm{ng} \mathrm{kg}^{-1} \mathrm{~h}^{-1}$, an order of magnitude larger than reported here. Aside from the different woodland sites studied, the earlier measurements spanned only autumn and winter, rather than the full year of the current study, so the elevated emissions during autumn would upwardly bias the derived average. Also, Drewer et al. enclosed litter samples for a few minutes only, therefore minimising any effect of prolonged enclosure times, whilst samples in this study were enclosed for longer, therefore maximising precision but potentially at a cost of accuracy. A further issue is that Drewer et al. (2008), did not directly account for blank effects but checked for blank fluxes only once at the beginning of their study. This may have led to an overestimation of net fluxes since fluxes in general were very low and very often small emissions were observed from the blank enclosures themselves. Since Drewer et al. used the same enclosures used in this study it is likely that the blank effect observed here also applies to their study as well. Ultimately, however, it is not possible to determine the exact reason for the apparent difference between the two studies. The mean litter fluxes measured in Borneo by our group were $1.4 \pm 0.7 \mathrm{ng} \mathrm{kg}^{-1} \mathrm{~h}^{-1}$ and $2.3 \pm 1.0 \mathrm{\mu g} \mathrm{kg}^{-1} \mathrm{~h}^{-1}$ 
for $\mathrm{CH}_{3} \mathrm{Br}$ and $\mathrm{CH}_{3} \mathrm{Cl}$, respectively (Blei et al., 2010a). These values are of similar magnitude to those presented here. Furthermore, the ratio of mean $\mathrm{CH}_{3} \mathrm{Cl}$ to $\mathrm{CH}_{3} \mathrm{Br}$ emissions of $\sim 1600$ found in Borneo also indicated that tropical leaf litter is relatively more important as a $\mathrm{CH}_{3} \mathrm{Cl}$ source than as a $\mathrm{CH}_{3} \mathrm{Br}$ source, similar to this study. However, it is again stressed that uptake rates might be underestimated so average fluxes presented here have to be regarded as upper limits.

\subsection{Griffin Forest (coniferous litter)}

Mean $( \pm 1 \mathrm{sd})$ net $\mathrm{CH}_{3} \mathrm{Br}$ and $\mathrm{CH}_{3} \mathrm{Cl}$ fluxes from needle litter were $5.7 \pm 6.3$ ng kg-1 $\mathrm{h}^{-1}$ and $0.47 \pm 0.14 \mathrm{\mu g} \mathrm{kg}^{-1} \mathrm{~h}^{-1}$, respectively. There was a significant difference (two-tailed $t$-test) in gravimetric water content between the samples in the thinned and un-thinned sections of the forest at $P \approx 6 \times 10^{-6}$ with mean values of $36 \%$ and $57 \%$, respectively. However, there was no significant difference between net methyl halide fluxes from these two sections at $P<0.05$. This again indicates that water content does not influence methyl halide emissions from natural litter material for the ambient temperatures experienced in this study (up to $16{ }^{\circ} \mathrm{C}$ ). Although mean methyl halide fluxes at Fir Links and Griffin Forest were similar it seems from previously reported measurements (Drewer et al., 2008) and preliminary studies for this work that needle litter is more often an emitter than is the case for leaf litter. As with the discussion above (Section 4.1.4.) on decdiuous litter data, Drewer et al. (2008) reported net emissions from needle litter (at Griffin Forest) about an order of magnitude larger than fluxes found in this study and the same reasons for this discrepancy likely apply.

\subsection{Tentative scale-up of litter fluxes and global implications}

Assuming the data from Fir Links and Griffin Forest are representative of temperate deciduous and coniferous forests worldwide a very crude scale up is derived by multiplying the data from the two sites with the areas for deciduous and coniferous forest and woodland globally of $15.8 \times 10^{12} \mathrm{~m}^{2}$ and $12.1 \times 10^{12} \mathrm{~m}^{2}$, respectively, and estimated litter pools (UNESCO, 1973; Matthews, 1997). The resulting fluxes are $0.6 \%$ and $5 \%$, respectively, of the current estimated $\mathrm{CH}_{3} \mathrm{Br}$ and $\mathrm{CH}_{3} \mathrm{Cl}$ global annual turnovers of $200 \mathrm{Gg} \mathrm{yr}^{-1}$ and $4400 \mathrm{Gg} \mathrm{yr}^{-1}$ (Montzka et al., 2002; Clerbaux et al., 2007). Therefore nonwoody leaf and needle litter from temperate forests is unlikely to be important for the global $\mathrm{CH}_{3} \mathrm{Br}$ budget but possibly a moderate source for the $\mathrm{CH}_{3} \mathrm{Cl}$ budget. Similar conclusions have been noted for vegetation and 
litter in tropical forests (Blei et al., 2010a). Given the strong variability of fluxes over time and the lack of understanding of what is ultimately driving uptake and emission processes of methyl halides from leaf and needle litter a more precise quantification is avoided. However, it should be noted the above statements relate to the nonwoody proportion of forest litter, which was taken to be $30 \%$ of total litter mass (Matthews, 1997); decomposition of the $70 \%$ coarse woody detritus mass will likely also contribute flux.

\section{Conclusions}

This study has reported the first measurements of $\mathrm{CH}_{3} \mathrm{Cl}$ fluxes from temperate forest nonwoody leaf litter. Long-term average fluxes were found to be of the order of $0.1 \mu \mathrm{g} \mathrm{kg}^{-1} \mathrm{~h}^{-1}$. Considering the large area of temperate forests this makes leaf litter a potentially important source of $\mathrm{CH}_{3} \mathrm{Cl}$ globally.

Observed $\mathrm{CH}_{3} \mathrm{Br}$ fluxes, augmenting measurements already available, were two orders of magnitude smaller than $\mathrm{CH}_{3} \mathrm{Cl}$ fluxes, making nonwoody leaf litter unlikely to be an important $\mathrm{CH}_{3} \mathrm{Br}$ source globally, although previous measurements on $\mathrm{CH}_{3} \mathrm{Br}$ have suggested that fluxes in temperate forests may be an order of magnitude larger than observed here. Furthermore, no coarse woody detritus or live plants such as trees were included in this study, adding further potential to the importance of temperate forests to global methyl halide budgets.

Fluxes from deciduous leaf litter were shown to vary significantly more over the duration of a year compared with spatial variability. However, on average, net fluxes for a given methyl halide were comparable between deciduous and coniferous litter. In general the $\mathrm{CH}_{3} \mathrm{Cl}$ and $\mathrm{CH}_{3} \mathrm{Br}$ fluxes were temporally well correlated. The $\mathrm{CH}_{3} \mathrm{Cl} / \mathrm{CH}_{3} \mathrm{Br}$ mass ratio derived from the mean flux values of all litter samples was $\sim 200$, about 10 times larger than the ratio derived from global turnover estimates. Future studies should investigate the extent to which in situ fluxes from leaf and needle litter are the product of abiotic chemical reactions or microbial/fungal activity.

\section{Acknowledgements}

We gratefully acknowledge University of Edinburgh studentship funding to EB. We thank Benjamin S. Gilfedder of the Technical University of Braunschweig and Andriy K. Cheburkin of the Ruprecht-Karls University of Heidelberg for assistance with XRF measurements. 


\section{References}

Blei, E., Hardacre, C.J., Mills, G.P., Heal, K.V., Heal, M.R., 2010a. Identification and quantification of methyl halide sources in a lowland tropical rainforest. Atmospheric Environment 44, 1005-1010.

Blei, E., Heal, K.V., Heal, M.R., 2010b. Long-term $\mathrm{CH}_{3} \mathrm{Br}$ and $\mathrm{CH}_{3} \mathrm{Cl}$ flux measurements in temperate salt marshes. Biogeosciences Discussions 7, in press.

Cheburkin, A.K., Shotyk, W., 2005. Energy-dispersive XRF spectrometer for Ti determination (TITAN). X-ray Spectrometry 34, 69-72.

Clerbaux, C., Cunnold, D., Anderson, J., Engel, A., Fraser, P., Mahieu, E., Manning, A., Miller, J., Montzka, S., Nassar, R., Prinn, R., Reimann, S., Rinsland, C., Simmonds, P., Verdonik, D., Weiss, R., Wuebbles, D., Yokouchi, Y., 2007. Scientific Assessment of Ozone Depletion: 2006. World Meteorological Organization. chapter 1: Long-Lived Compounds.

Cox, M.L., Fraser, P.J., Sturrock, G.A., Siems, S.T., Porter, L.W., 2004. Terrestrial sources and sinks of halomethanes near Cape Grim, Tasmania. Atmospheric Environment 38, 3839-3852.

Dimmer, C.H., Simmonds, P.G., Nickless, G., Bassford, M.R., 2001. Biogenic fluxes of halomethanes from Irish peatland ecosystems. Atmospheric Environment 35, 321-330.

Drewer, J., Heal, K.V., Smith, K.A., Heal, M.R., 2008. Methyl bromide emissions to the atmosphere from temperate woodland ecosystems. Global Change Biology 14, 2539-2547.

Drewer, J., Heal, M.R., Heal, K.V., Smith, K.A., 2006. Temporal and spatial variation in methyl bromide flux from a salt marsh. Geophysical Research Letters 33, L16808, doi: 10.1029/2006GL026814.

Fahey, D.W., 2007. Scientific Assessment of Ozone Depletion: 2006. World Meteorological Organization, Geneva, Switzerland. chapter Twenty questions and answers about the ozone layer: 2006 update.

Hamilton, J.T.G., McRoberts, W.C., Keppler, F., Kalin, R.M., Harper, D.B., 2003. Chloride methylation by plant pectin: An efficient environmentally significant process. Science 301, 206-209. 
Hardacre, C.J., Blei, E., Heal, M.R., 2009. Growing season methyl bromide and methyl chloride fluxes at a sub-arctic wetland in Sweden. Geophysical Research Letters 36, L12401, doi: 10.1029/2009GL038277.

Ibrom, A., Jarvis, P., Clement, R., Morgenstern, K., Oltchev, A., Medlyn, B., Wang, Y., Wingate, L., Moncrieff, J., Gravenhorst, G., 2006. A comparative analysis of simulated and observed photosynthetic $\mathrm{CO}_{2}$ uptake in two coniferous forest canopies. Tree Physiology 26, 845-864.

Jeffers, P.M., Wolfe, N.L., Nzengung, V., 1998. Green plants: A terrestrial sink for atmospheric $\mathrm{CH}_{3} \mathrm{Br}$. Geophysical Research Letters 25, 43-46.

Lee-Taylor, J.M., Holland, E.A., 2000. Litter decomposition as a potential natural source of methyl bromide. Journal of Geophysical Research 105, $8857-8864$.

Lobert, J., Keene, W., Logan, J., Yevich, R., 1999. Global chlorine emissions from biomass burning: Reactive chlorine emissions inventory. Journal of Geophysical Research 104, 8373-8389.

Manley, S.L., Wang, N.Y., Walser, M.L., Cicerone, R.J., 2006. Coastal salt marshes as global methyl halide sources from determinations of intrinsic production by marsh plants. Global Biogeochemical Cycles 20, GB3015, doi: 10.1029/2005GB002578.

Matthews, E., 1997. Global litter production, pools, and turnover times: Estimates from measurement data and regression models. Journal of Geophysical Research 102, 18771-18800.

Montzka, S., Fraser, P., Butler, J., Connell, P., Cunnold, D., Daniel, J., Derwent, R., Lal, S., McCulloch, A., Oram, D., Reeves, C., Sanhueza, E., Steele, L., Velders, G., Weiss, R., Zander, R., 2002. Scientific Assessment of Ozone Depletion: 2002. World Meteorological Organization. chapter 1: Controlled Substances and Other Source Gases.

Rhew, R.C., Aydin, M., Saltzman, E.S., 2003. Measuring terrestrial fluxes of methyl chloride and methyl bromide using a stable isotope tracer technique. Geophysical Research Letters 30, 2103, doi: 10.1029/2003GL018160. 
Rhew, R.C., Miller, B.R., Weiss, R.F., 2000. Natural methyl bromide and methyl chloride emissions from coastal salt marshes. Nature 403, 292-295.

Serca, D., Guenther, A., Klinger, L., Helmig, D., Hereid, D., Zimmerman, P., 1998. Methyl bromide deposition to soils. Atmospheric Environment 32, 1581-1586.

UNESCO, 1973. International Classification and Mapping of Vegetation. Technical Report. UNESCO. Paris.

Watling, R., Harper, D.B., 1998. Chloromethane production by wood-rotting fungi and an estimate of the global flux to the atmosphere. Mycological Research 102, 769-787.

Wishkerman, A., Gebhardt, S., McRoberts, C.W., Hamilton, J.T.G., Williams, J., Keppler, F., 2008. Abiotic methyl bromide formation from vegetation, and its strong dependence on temperature. Environmental Science \& Technology 42, 6837-6842.

Yassaa, N., Wishkerman, A., Keppler, F., Williams, J., 2009. Fast determination of methyl chloride and methyl bromide emissions from dried plant matter and soil samples using HS-SPME and GC-MS: method and first results. Environmental Chemistry 6, 311-318.

Yvon-Lewis, S.A., Saltzman, E.S., Montzka, S.A., 2009. Recent trends in atmospheric methyl bromide: analysis of post-montreal protocol variability. Atmospheric Chemistry and Physics 9, 5963-5974. 